\title{
La voluntad de la sociedad anónima $y$ las juntas de accionistas
}

\author{
Hernando Montoya Alberti
}

\section{Introducción}

A diferencia del empresario individual, quien adopta sus decisiones en forma individual e inconsultamente, en el régimen societario las decisiones se adoptan bajo un régimen especializado en el cual se debe dar garantías a los socios para que manifiesten su voluntad bajo un sistema de decisiones mayoritarias y de concurrencia mínima.

En el caso del empresario individual no es necesario que se otorgue garantías respecto a la forma de establecer sus decisiones, pues es él quien las adopta de forma inconsulta, no tiene socio alguno de por medio, el negocio es individual. Cuando se constituye una sociedad, las decisiones tienen su sede en el órgano supremo como es la junta de socios, y por tanto debe respetarse la voluntad de los socios. La Ley General de Sociedades (LGS) respeta en todas las sociedades la voluntad mayoritaria de los socios, sea que se exprese por razón de las personas, o por razón de los aportes representados en el capital social. Así, por ejemplo, en la sociedad colectiva, la voluntad se forma por decisión de los socios, y según el artículo 269 los acuerdos de la sociedad se adoptan por mayoría de votos, computados por personas, salvo pacto distinto, $\mathrm{y}$, en el supuesto que se pacte que la mayoría se computa por capitales, el pacto social debe establecer el voto que corresponde al socio o a los socios industriales; $\mathrm{y}$, en el caso de que un socio tenga más de la mitad de los votos, se necesitará además el voto de otro socio. 
Las reglas sobre formación de la voluntad social de la sociedad colectiva se aplican a la sociedad comanditaria simple, y las reglas de la sociedad anónima a la sociedad comanditaria por acciones, con las limitaciones reguladas para cada modalidad societaria. En el caso de la sociedad de responsabilidad limitada, "La voluntad de los socios que representen la mayoría del capital social regirá la vida de la sociedad" (artículo 286). Finalmente, en el caso de las sociedades civiles, el artículo 301 dispone que "Los acuerdos se adoptan por mayoría de votos computados conforme al pacto social y, a falta de estipulación, por capitales y no por personas". En el caso de contar con socios que aportan su profesión u oficio, el peso para las decisiones se aplica con un porcentaje igual al valor promedio de los aportes de los socios capitalistas. En lo que se refiere a la modificación del pacto social, requiere un acuerdo unánime de los socios.

Sin entrar en más detalles, podemos apreciar que la formación de la voluntad de la sociedad se adopta a través de la expresión de sus socios en forma mayoritaria, y por excepción en forma unánime. La voluntad se forma en plena junta general de socios, con las excepciones que se establecen en la ley; así, por ejemplo, el artículo 286 de la Ley General de Sociedades (Ley n. ${ }^{\circ}$ 26887) dispone que:

[...] el estatuto determina la forma y manera como se expresa la voluntad de los socios, pudiendo establecer cualquier medio que garantice su autenticidad. La junta será obligatoria si solicitan su realización, socios que representen por lo menos la quinta parte del capital social.

Con lo señalado, es posible entonces situarnos en el mismo supuesto en que se sitúa el artículo 170 de la LGS, cuando en concordancia con lo señalado para las decisiones del directorio, regula los casos en que no haya habido sesión, supuesto en el cual se requiere que en el documento que refleje la decisión conste la aprobación unánime de todos los directores. Nos llama la atención la aplicación del artículo 286, sin embargo; está concebido para el caso de sociedades de un número reducido de accionistas, sociedades cerradas al grupo y posiblemente de naturaleza familiar, en donde el rigor en la formación de la voluntad en junta es innecesario y es más eficiente levantar un acta de acuerdos unánimes de socios, respetándose siempre la obligatoriedad de la celebración de la junta general cuando soliciten su realización socios que representen por lo menos la quinta parte del capital social. Al respecto, es pertinente advertir que en el año 1966, cuando se promulga la Ley de 
Sociedades Mercantiles n. ${ }^{\mathrm{o}}$ 16123, el concepto de sesiones virtuales no era común en nuestro lenguaje, por tanto la redacción original de la norma no podía hacer alusión a otra posibilidad más que la suscripción de acuerdos sin necesidad de realización de sesión de socios.

Conforme nos refiere Rodrigo Uría (1999):

La sociedad anónima, como entidad jurídica dotada de personalidad, necesita valerse de órganos para el despliegue de su actividad interna y externa... Los órganos sociales emanan en personas físicas o en pluralidades de personas investidas por la ley de la función de manifestar la voluntad del ente o de ejecutar y cumplir esa voluntad, desarrollando las actividades jurídicas necesarias para la consecución de los fines sociales. (p. 309)

\section{Las juntas de accionistas}

Se hará referencia a partir de ahora a las sesiones de accionistas, es decir, a aquellas reuniones de socios cuya participación en el capital social de la sociedad está representada por acciones, y en donde cada acción da lugar a un voto. Las decisiones tomadas con la formalidad establecida en la ley obligan a la sociedad, y los socios deben respetar sus acuerdos y decisiones.

El artículo 111 de la LGS otorga a la junta general de accionistas su majestuosidad cuando la reconoce como el órgano supremo de la sociedad, y la impone como aquella reunión en la que los accionistas deben constituirse en junta general debidamente convocada, $\mathrm{y}$, con el quórum correspondiente, decidir, por la mayoría que establece esta ley, los asuntos propios de su competencia. Todos los accionistas, incluso los disidentes y los que no hubieren participado en la reunión, están sometidos a los acuerdos adoptados por la junta general.

\section{Legitimación para la convocatoria a juntas generales de accionistas}

La norma citada refiere que la junta general debe estar debidamente convocada, lo que quiere decir que debemos definir quién es la persona o el órgano que debe convocar, y la forma de hacerlo.

$\mathrm{Al}$ respecto, tenemos que el artículo 113 señala que es el directorio, o en su caso la administración de la sociedad, quien convoca a junta general. 
Si se trata del directorio es necesario entonces contemplar la existencia de un acuerdo previo de directorio que decida la convocatoria a junta general; no se trata de que cualquier director decida convocar, más bien se trata del órgano colegiado que toma sus acuerdos en la forma establecida en la misma ley. En tal caso, se requiere que los directores sean citados a sesión de directorio con la formalidad establecida en la ley, y que adopten sus decisiones por mayoría de votos. Si el directorio adopta su decisión y decide no convocar a junta general de accionistas, simplemente no existe amparo legal para exigir por terceros la convocatoria; y si se trata de accionistas, entonces la ley les alberga la posibilidad de recurrir al juez o al notario para que convoque a junta si el pedido ha sido rechazado por el directorio, o si no se han previsto en la agenda con la cual se cita los puntos solicitados para debatir en junta. En tal caso, ante solicitud de accionistas, el juez ordena la convocatoria ${ }^{1}$, señalando lugar, día y hora, así como la persona que presidirá la junta. La expresión del derecho de protección al accionista minoritario se da en el artículo $119^{2}$ de la LGS, que dispone que:

1 Artículo 117.- Convocatoria a solicitud de accionistas.

Cuando uno o más accionistas que representen no menos del veinte por ciento (20\%) de las acciones suscritas con derecho a voto soliciten notarialmente la celebración de la junta general, el directorio debe indicar los asuntos que los solicitantes propongan tratar.

La junta general debe ser convocada para celebrarse dentro de un plazo de quince (15) días de la fecha de publicación de la convocatoria.

Si la solicitud a que se refiere el acápite anterior fuese denegada o transcurriesen más de quince (15) días de presentada sin efectuarse la convocatoria, el o los accionistas, acreditando que reúnen el porcentaje exigido de acciones, pueden solicitar al notario y/o al juez de domicilio de la sociedad que ordene la convocatoria, que señale lugar, día y hora de la reunión, su objeto, quién la preside, con citación del órgano encargado, y, en caso de hacerse por vía judicial, el juez señala al notario que da fe de los acuerdos.

2 Artículo 119.- Convocatoria judicial.

Si la junta obligatoria anual o cualquier otra ordenada por el estatuto no se convoca dentro del plazo y para sus fines, o en ellas no se tratan los asuntos que corresponden, es convocada a pedido del titular de una sola acción suscrita con derecho a voto, ante el notario o el juez del domicilio social, mediante trámite o proceso no contencioso.

La convocatoria judicial o notarial debe reunir los requisitos previstos en el artículo 116. 
Si la junta obligatoria anual o cualquier otra ordenada por el estatuto no se convoca dentro del plazo y para sus fines, o en ellas no se tratan los asuntos que corresponden, es convocada a pedido del titular de una sola acción suscrita con derecho a voto, ante el notario o el juez del domicilio social [...]

En ese sentido, Beaumont Callirgos (2000) califica este derecho como un derecho de minoría en su máxima expresión, y que la ley no limita ese derecho al titular de una sola acción, sino al titular de por lo menos una acción.

El objeto de la convocatoria de la junta obligatoria anual (JOA), es pronunciarse sobre la gestión social, debiendo el directorio rendir cuenta de la gestión mediante los estados financieros puestos a disposición de los accionistas. Los accionistas tienen derecho a que se les rinda cuenta de la gestión, y la forma como la ley ha previsto este derecho es a través del informe que debe presentar el directorio, como responsable de la gestión, ante la junta general de accionistas; en esta forma se rinde cuentas societariamente, a diferencia de los negocios asociativos, en los cuales cabe la rendición de cuentas contractual y la judicial, con su facción de inventarios si fuera el caso. En la fase societaria, la forma de rendir cuentas varía, pues obliga al cuerpo colegiado administrador a rendirla y al accionista se le otorga derechos mínimos para recurrir a la autoridad judicial para que convoque para tal efecto. Por ello, ante la falta de convocatoria, para tomar nota del rendimiento de la gestión es que la ley autoriza al titular de una acción a pedir al juez y/o al notario se convoque para dichos efectos. El artículo 119 ha ampliado este derecho a otras juntas que hayan sido previstas en el estatuto, como por ejemplo las juntas para evaluar periódicamente la gestión social.

En cuanto al plazo para convocar a JOA, la ley ${ }^{3}$ dispone que esta junta debe convocarse cuando menos una vez al año dentro de los tres meses siguientes a la terminación del ejercicio económico; en consecuencia, transcurridos los tres meses de terminado el ejercicio económico, el titular de una sola acción podrá pedir al juez o al notario convoque a junta general de accionistas para tratar temas propios de la JOA.

3 Artículo 114 LGS. 
Salvo los casos de excepción antes comentados, lo regular es que conforme al artículo $113^{4}$ de la LGS, la legitimación activa para convocar recaiga en el directorio y también en la administración de la sociedad. No nos cabe la menor duda de que el directorio es el órgano por excelencia, y, por ley, al que se le atribuye la facultad y el deber de convocar a junta general de accionistas, pero la ley hace referencia también a la administración. Debemos entender que el directorio es la administración, pero también puede hacer extensiva esta alocución a la gerencia de la sociedad, en cuyo caso habría que dilucidar el límite de esta facultad o si en realidad existe esta duplicidad. Al respecto debe advertirse que en las sociedades anónimas cerradas, en las cuales existe la posibilidad de prescindir del directorio y mantener únicamente a la gerencia de la sociedad, por disposición legal, corresponde a la gerencia general asumir las facultades asignadas al directorio, por tanto, en la remisión del artículo 113 de la LGS, debe entenderse que la administración que tiene la facultad de convocar a junta es precisamente el gerente general, en aquellas sociedades anónimas cerradas donde no exista el órgano directorio ${ }^{5}$. En todo caso cabría preguntarse cuáles son los casos de excepción en los que la administración puede convocar a junta general de accionistas. Al respecto traemos a colación el artículo 158 de la LGS, que contempla la situación de las sociedades ante la vacancia múltiple de directores ${ }^{6}$,

4 Artículo 113.- Convocatoria a la Junta.

El directorio o en su caso la administración de la sociedad convoca a junta general cuando lo ordena la ley, lo establece el estatuto, lo acuerda el directorio por considerarlo necesario al interés social o lo solicite un número de accionistas que represente cuando menos el veinte por ciento de las acciones suscritas con derecho a voto.

5 Artículo 247.- Directorio facultativo.

En el pacto social o en el estatuto de la sociedad se podrá establecer que la sociedad no tiene directorio.

Cuando se determine la no existencia del directorio, todas las funciones establecidas en esta ley para este órgano societario serán ejercidas por el gerente general.

6 Artículo 158.- Vacancias múltiples.

En caso de que se produzca vacancia de directores en número tal que no pueda reunirse válidamente el directorio, los directores hábiles asumirán provisionalmente la administración y convocarán de inmediato a las juntas de accionistas que corresponda para que elijan nuevo directorio. De no hacerse esta convocatoria o de haber vacado el cargo de todos los directores, corresponderá al gerente 
hecho que no permite que el directorio se reúna válidamente por falta de quórum. En tal caso, la misma norma autoriza que los directores hábiles, es decir, los que no han vacado en el cargo, asuman provisionalmente la administración y convoquen de inmediato a las juntas de accionistas que correspondan para que elijan nuevo directorio. Como apreciamos en este supuesto, ante la imposibilidad de que se reúna el directorio y pueda convocar, porque el número de directores no lo permite en tanto no puede conformar el quórum, la ley otorga esta facultad a los directores hábiles, quienes ya no pueden formar cuerpo colegiado, sino que se posa en ellos la facultad de administrar provisionalmente la sociedad directamente, entendiéndose en forma conjunta, pues se escapa a la institucionalidad del órgano colegiado, precisamente por falta de quórum.

La LGS contiene otras excepciones para indicar quién es la persona $\mathrm{u}$ órgano designado para realizar las convocatorias, y entre estos otros casos podemos citar la facultad que tiene el representante de los obligacionistas para "convocar a la junta de accionistas o de socios, según el caso, de la sociedad emisora si ocurriese un atraso mayor de ocho días en el pago de los intereses vencidos o en la amortización del principal" (numeral 7, artículo 325); o en el caso del liquidador de la sociedad, a quien, por disposición del artículo 416, numeral 10, le corresponde:

[...] convocar a la junta general cuando lo consideren necesario para el proceso de liquidación, así como en las oportunidades señaladas en la ley, el estatuto, el pacto social, los convenios entre accionistas inscritos ante la sociedad o por disposición de la junta general.

En lo que se refiere a las sociedades anónimas abiertas (SAA), la Ley 30050 ha modificado el artículo 255 de la LGS y dispone que la solicitud de convocatoria por los accionistas que represente el $5 \%$ de las acciones suscritas con derecho a voto, se haga ante el notario o el juez. Dicho criterio se aplica igual para las juntas especiales. El notario o el juez del domicilio de la sociedad dispondrán la convocatoria, siempre que el directorio de la sociedad inscrito en los registros públicos o el órgano que ejerza las funciones del mismo hubiese denegado el pedido de manera expresa o tácita. Se presume la denegación tácita:

general realizar de inmediato dicha convocatoria. Si las referidas convocatorias no se produjesen dentro de los diez días siguientes, cualquier accionista puede solicitar al juez que la ordene, por el proceso sumarísimo. 
(i) Cuando el directorio no hubiese convocado a junta en el plazo establecido en el tercer párrafo del artículo 117 de esta ley, es decir, dentro de los tres meses de concluido el periodo económico.

(ii) Cuando el directorio deje sin efecto, suspenda o bajo cualquier forma altere o modifique los términos de la convocatoria que hubiere realizado a solicitud del referido porcentaje de accionistas.

(iii) Cuando el directorio hubiese dispuesto la celebración de la junta dentro de un plazo mayor de cuarenta (40) días desde la publicación del aviso de convocatoria.

\section{Formalidad de las convocatorias}

En cuanto a la forma de convocatoria, tenemos que señalar que la convocatoria tiene una formalidad destinada a garantizar al accionista el conocimiento de los temas a tratar, la seguridad del medio de comunicación y la garantía del plazo para conocer con anticipación los asuntos materia de la sesión.

Así tenemos, en primer lugar, que el convocante debe hacerlo respetando lo señalado en el estatuto y que las acciones a realizar estén en armonía con la ley. Es así como en el caso de las sociedades anónimas, estas se deben convocar mediante publicaciones en diarios; si la sociedad está domiciliada en Lima o Callao, es obligatoria la convocatoria en el diario oficial El Peruano y en uno de mayor circulación de la provincia; en tanto que si la sociedad es domiciliada en provincias, debe publicitarse la convocatoria en el periódico encargado de la inserción de los avisos judiciales en esa provincia ${ }^{7}$. La excepción a la publicación está dada para la sociedad anónima cerrada, sociedad en la cual, a similitud de la sociedad

7 Artículo 43.- Publicaciones. Incumplimiento.

Las publicaciones a que se refiere esta ley serán hechas en el periódico del lugar del domicilio de la sociedad, encargado de la inserción de los avisos judiciales.

Las sociedades con domicilio en las provincias de Lima y Callao harán las publicaciones cuando menos en el diario oficial El Peruano y en uno de los diarios de mayor circulación de Lima o del Callao, según sea el caso.

La falta de la publicación, dentro del plazo exigido por la ley, de los avisos sobre determinados acuerdos societarios en protección de los derechos de los socios o de terceros, prorroga los plazos que la ley confiere a éstos para el ejercicio de sus derechos, hasta que se cumpla con realizar la publicación. 
de responsabilidad limitada, las convocatorias se hacen mediante esquelas con cargo de recepción, facsímil, correo electrónico u otro medio de comunicación que permita obtener constancia de recepción, dirigidos al domicilio o a la dirección designada por el accionista para este efecto. Resulta importante entonces advertir que no existe medio sustitutorio del cargo de recepción, en tal sentido no satisface el requisito de la publicación por el diario de la convocatoria a junta de accionistas de una sociedad anónima cerrada, pues la publicación no premune de cargo de recepción alguno. Por otro lado, resulta importante advertir que la esquela debe ser remitida al domicilio del accionista, o a la dirección designada por el accionista, debiendo entenderse que existiendo esta manifestación, toda esquela remitida a dicho lugar será recepcionada por el accionista, y por tanto resulta válida la convocatoria. Al respecto, merece especial cuidado entonces que ante la transmisión de acciones en una sociedad anónima cerrada se deba prever la obligación del nuevo socio de declarar su domicilio ante la sociedad, o la dirección a la cual se le deben enviar las esquelas de convocatoria a junta general de accionistas.

\section{Plazos de convocatoria}

Cuando se trata de la convocatoria a junta general de accionistas en las sociedades anónimas abiertas y en las sociedades anónimas ordinarias, la convocatoria debe ser siempre por periódico, tal como lo advertimos anteriormente. Sin embargo, los plazos para la publicación varían: tratándose de las sociedades anónimas ordinarias, es decir, las que no son abiertas ni cerradas, la publicación se hace con diez días de anticipación, al igual que para aquellas juntas previstas en el estatuto, las que podríamos llamar juntas estatutarias; en cambio, para las demás juntas generales, el término para la anticipación de la publicación es de tres días, comenzándose a computar el plazo desde el día siguiente de la publicación. En una misma publicación se puede citar para las juntas generales, es decir, para la primera fecha de convocatoria, y luego, de no haber quórum para la primera citación, en el mismo aviso se fijará la segunda fecha, indicando lugar día y hora. Cuando se trata de convocatoria a juntas generales de las sociedades anónimas abiertas, los plazos son más extendidos: la primera convocatoria se hará con veinticinco días de anticipación, y si se aprovecha el mismo aviso de convocatoria, podrá fijarse la fecha para la segunda y tercera convocatorias, mediando entre estas dos fechas un plazo no menor de tres días ni 
mayor de diez días, con la finalidad de no permitir que las convocatorias se dilaten demasiado tiempo y que los accionistas puedan perder el interés en la sesión, o que, simplemente por el transcurso del tiempo, pueda pasar desapercibida en el momento preciso, lo cual no sucede en el caso de las otras sociedades en donde la ley no fija periodos movibles sino que se fija un plazo máximo de diez días o de tres días si se trata de segunda convocatoria. De no convocarse en un solo aviso a junta general de las SAA, el plazo se difiere a los treinta días entre la segunda y la tercera convocatorias.

Es importante advertir que en el caso de las sociedades anónimas abiertas, la Ley n. ${ }^{\circ} 30050$ ha modificado el artículo 256 de la LGS, estableciendo que en las SAA el derecho de concurrencia a la junta corresponde a los accionistas que aparezcan inscritos como totales con una anticipación de diez días. Nos advierte el profesor Hunsdkopf (2009, p. 139) que cuando se trata de juntas generales convocadas para tomar acuerdos sobre la fusión o escisión de la sociedad, la anticipación de la publicación es de diez días, con lo cual se establece un régimen distinto para la adopción de acuerdos que impliquen la reorganización societaria por la vía de la fusión y la escisión.

\section{Contenido de la agenda}

Dentro de la formalidad de la convocatoria nos cumple agregar que la convocatoria contenida en la esquela o en el aviso de convocatoria debe contener requisitos establecidos puntualmente por la ley; ellos son: el lugar, día y hora de celebración de la junta general, así como los asuntos a tratar. Dicha precisión es importante por cuanto el accionista tiene el derecho de asistir a la junta o no, dependerá de la importancia del tema que corresponda tratar para asistir a la sesión, y además, conociendo en forma anticipada los temas a tratar, podrá prepararse y obtener la información que la ley le permite a través de los pedidos antes de la junta general o dentro de la junta general, conforme a lo señalado en los artículos $130^{8}$ y 131. En situación similar se sitúa la ley cuando en el artícu-

8 Art. 130.- Desde el día de la publicación de la convocatoria, los documentos, mociones y proyectos relacionados con el objeto de la junta general deben estar a disposición de los accionistas en las oficinas de la sociedad o en el lugar de celebración de la junta general, durante el horario de oficina de la sociedad. 
lo 224 dispone que en el caso de la aprobación de los estados financieros, los accionistas puedan obtener información fotocopiada de los documentos sustentatorios, a diferencia del artículo 130, en que solo se otorga el derecho a la información pero no a obtener copias. En este sentido, Hundskopf (2009) señala:

[...] el derecho de información se encuentra vinculado con el voto, y se refiere a la posibilidad de que, antes de asistir a las deliberaciones y emitir su voto en la junta general, el accionista cuente con los elementos de juicio suficientes. (p. 146)

Cuando esta información se pida en plena junta y motive la suspensión de la junta, se establece la excepción del directorio de brindarla cuando considere que la publicidad solicitada pueda perjudicar los intereses de la sociedad.

La información solicitada fuera de junta, y en cualquier oportunidad, está regulada por el artículo 52-A, el cual establece la obligación de las sociedades anónimas de proporcionar, a solicitud escrita de accionistas que representen al menos el cinco por ciento (5\%) del capital pagado de la sociedad, información respecto de la sociedad y sus operaciones, siempre que no se trate de hechos reservados o de asuntos cuya divulgación pueda causar daños a la sociedad. En caso de discrepancia sobre el carácter reservado o confidencial de la información, resuelve el juez del domicilio de la sociedad.

\section{Clases de juntas de accionistas}

\subsection{La junta general de accionistas}

La Ley contempla diversas clases de junta de accionistas. Entre ellas tenemos la junta general, es decir, aquella que congrega a todos los accionistas, cualquiera sea la condición de accionista o clase de accionista; aquí se reúnen los titulares de acciones comunes, como aquellos que son

Los accionistas pueden solicitar con anterioridad a la junta general o durante el curso de la misma, los informes o aclaraciones que estimen necesarios acerca de los asuntos comprendidos en la convocatoria. El directorio está obligado a proporcionárselos, salvo en los casos en que juzgue que la difusión de los datos solicitados perjudique el interés social. [...] 
titulares de acciones con derechos especiales. En la junta general se tratan los temas propios de su competencia, contemplada en los artículos 114 y 115 de la LGS.

Así, por ejemplo, es un asunto propio de la competencia de la junta, convocar a todos los accionistas para tratar sobre la gestión social y los resultados económicos del ejercicio anterior, expresados en los estados financieros del ejercicio anterior; resolver sobre la aplicación de las utilidades, si las hubiere; elegir cuando corresponda a los miembros del directorio y fijar su retribución; designar o delegar en el directorio la designación de los auditores externos, cuando corresponda; y resolver sobre los demás asuntos que sean propios conforme al estatuto y sobre cualquier otro consignado en la convocatoria. En este último supuesto podríamos considerar dentro de su competencia los asuntos precisados para las juntas fijadas en el estatuto.

Merece comentario, la competencia fijada para elegir a los miembros del directorio. La norma señala que esta competencia procede cuando corresponda, para lo cual debemos precisar cuándo corresponde. Conforme al artículo 163, el estatuto señala la duración del directorio por períodos determinados, no mayores de tres años ni menores de uno. Si el estatuto no señala plazo de duración, se entiende que es por un año. El directorio se renueva totalmente al término de su período, incluyendo a aquellos directores que fueron designados para completar períodos. Los directores pueden ser reelegidos, salvo disposición contraria del estatuto. El período del directorio termina al resolver la junta general sobre los estados financieros de su último ejercicio y elegir al nuevo directorio, pero el directorio continúa en funciones, aunque hubiese concluido su período, mientras no se produzca nueva elección.

Lo señalado nos precisa que corresponde elegir al directorio regularmente, conforme a las pautas del artículo 163; y la diferencia de la competencia con la señalada en el artículo 115, se da cuando se trata de remociones y elección de directores, supuesto que no refleja una regularidad.

La junta general de accionistas tiene igualmente las facultades contempladas en el artículo 115, y son: 1. Remover a los miembros del directorio y designar a sus reemplazantes; 2. Modificar el estatuto; 3 . Aumentar o reducir el capital social; 4 . Emitir obligaciones; 5 . Acordar la enajenación, en un solo acto, de activos cuyo valor contable exceda el cincuenta por ciento del capital de la sociedad; 6 . Disponer investigaciones y auditorías 
especiales; 7. Acordar la transformación, fusión, escisión, reorganización y disolución de la sociedad, así como resolver sobre su liquidación; y 8 . Resolver en los casos en que la ley o el estatuto dispongan su intervención y en cualquier otro que requiera el interés social.

En el caso de los asuntos materia de la competencia de la junta general, podemos apreciar que no solo son los que se detallan en forma específica, sino que la norma deja abierta la posibilidad de asumir competencia en los casos que requiera el interés social. Dentro de esta competencia debemos advertir que la competencia de la administración de la sociedad le corresponde al directorio, es más, conforme a lo dispuesto en el artículo 172 de la LGS: “El directorio tiene las facultades de gestión y de representación legal necesarias para la administración de la sociedad dentro de su objeto, con excepción de los asuntos que la ley o el estatuto atribuyan a la junta general". Las limitaciones las puede fijar el estatuto, reservando ciertos aspectos de la administración al directorio. La ley ha fijado algunas facultades que son propias del directorio, pero la norma ha elegido limitarlas al seno de los accionistas por tratarse de supuestos muy importantes que tienen que ver con la disposición de los bienes de la sociedad. Así, por ejemplo, el inciso 5 del artículo 115 dispone que es competencia de la junta general: "Acordar la enajenación, en un solo acto, de activos cuyo valor contable exceda el cincuenta por ciento del capital de la sociedad". Dicho extremo de la norma ha tenido varias interpretaciones extensivas, en tanto que el origen se centraba en no disponer de activos fijos en esa proporción, en tanto que los activos fijos son activos productivos de la sociedad; y el deshacerse de ellos en términos significativos debería ser materia de aprobación por los accionistas, dado que se trata de los activos por los cuales se han podido realizar aportes a la sociedad, o en todo caso por velar por la permanencia de la empresa o del objeto social para el cual se constituyó. Por ello, la norma debería interpretarse en el sentido restrictivo, a efecto de no establecer los topes referenciales sobre los activos realizables, para permitir el funcionamiento ágil de la sociedad.

\subsection{Las juntas especiales de accionistas}

Estas juntas son aquellas en las que se reúnen los titulares de acciones de la misma especie, para discutir sobre sus derechos especiales otorgados por la sociedad al momento de suscribir o adquirir dichas acciones. Así, por ejemplo, la sociedad debe crear acciones comunes, que otorgan 
los derechos mínimos contenidos en el artículo $95^{9}$ de la LGS; pero también puede crear acciones, que además de los derechos comunes otorguen otros derechos, como por ejemplo otorgar la facultad de elegir a dos miembros del directorio, sin necesidad de sometimiento a la mayoría de la junta general de accionistas. Esta decisión la adoptan simplemente los titulares de acciones de la misma clase de acciones que disfrutan de ese derecho especial.

Para tomar este tipo de decisiones, los titulares de las acciones deben reunirse en junta especial que convoque y reúna a los titulares de dichas acciones para los efectos de tratar precisamente sobre sus derechos especiales. Las convocatorias, determinación de quórum y adopción de acuerdos se toman con las mismas reglas establecidas para las juntas generales.

Debemos marcar un margen para señalar que si bien la Ley General de Sociedades ha contemplado la creación y emisión de acciones sin derecho a voto, que cuentan con derechos especiales como el derecho a ser preferido en el reparto de la utilidad ${ }^{10}$, en la entrega del haber social, y su derecho a recibir obligatoriamente el dividendo preferencial otorgado, no es menos cierto que por tratarse de acciones sin derecho a voto, y conforme a lo dispuesto en el artículo $94^{11}$ de la LGS, dichas acciones

9 La acción con derecho a voto confiere a su titular la calidad de accionista y le atribuye, cuando menos, los siguientes derechos:

1. Participar en el reparto de utilidades y en el del patrimonio neto resultante de la liquidación;

2. Intervenir y votar en las juntas generales o especiales, según corresponda;

3. Fiscalizar en la forma establecida en la ley y el estatuto, la gestión de los negocios sociales;

4. Ser preferido, con las excepciones y en la forma prevista en esta ley, para:

a) La suscripción de acciones en caso de aumento del capital social y en los demás casos de colocación de acciones; y

b) La suscripción de obligaciones u otros títulos convertibles o con derecho a ser convertidos en acciones.

5. Separarse de la sociedad en los casos previstos en la ley y en el estatuto.

10 Artículo 97.- Las acciones sin derecho a voto dan a sus titulares el derecho a percibir el dividendo preferencial que establezca el estatuto. [...]

11 Artículo 94 LGS.- Puede crearse una o más clases de acciones sin derecho a voto. Las acciones sin derecho a voto no se computan para determinar el quórum de las juntas generales. 
no dan quórum, por tanto es imposible establecer un quórum en junta para accionistas sin derecho a voto; y además la ley no les otorga derecho a voto, con lo cual descarta cualquier posibilidad que pueda reunirse válidamente y tomar decisiones colectivas por mayoría de votos. En este caso, la ley otorga facultad, al titular de las acciones sin derecho a voto, para impugnar las decisiones que perjudiquen sus derechos, de lo cual se deduce que si la junta general adopta una decisión que lesione el derecho de los accionistas sin derecho a voto, estos, conforme al artículo $96^{12}$ de la LGS, podrán impugnar el acuerdo societario.

\subsection{Las juntas universales}

Las juntas universales son aquellas celebradas por los accionistas, sin necesidad de que sean convocados previamente, siempre que se encuentren presentes todos los titulares de las acciones de la sociedad.

12 Artículo 96.- Acciones sin derecho a voto.

La acción sin derecho a voto confiere a su titular la calidad de accionista y le atribuye, cuando menos, los siguientes derechos:

1. Participar en el reparto de utilidades y en el del patrimonio neto resultante de la liquidación con la preferencia que se indica en el artículo 97;

2. Ser informado cuando menos semestralmente de las actividades y la gestión de la sociedad;

3. Impugnar los acuerdos que lesionen sus derechos;

4. Separarse de la sociedad en los casos previstos en la ley y en el estatuto; y

5. En caso de aumento de capital:

a) A suscribir acciones con derecho a voto a prorrata de su participación en el capital, en el caso de que la junta general acuerde aumentar el capital únicamente mediante la creación de acciones con derecho a voto.

b) A suscribir acciones con derecho a voto de manera proporcional y en el número necesario para mantener su participación en el capital, en el caso de que la junta acuerde que el aumento incluye la creación de acciones sin derecho a voto, pero en un número insuficiente para que los titulares de estas acciones conserven su participación en el capital.

c) A suscribir acciones sin derecho a voto a prorrata de su participación en el capital, en los casos de aumento de capital en los que el acuerdo de la junta general no se limite a la creación de acciones con derecho a voto o en los casos en que se acuerde aumentar el capital únicamente mediante la creación de acciones sin derecho a voto. d) A suscribir obligaciones $u$ otros títulos convertibles o con derecho a ser convertidos en acciones, aplicándose las reglas de los literales anteriores según corresponda a la respectiva emisión de las obligaciones o títulos convertibles. 
Sin embargo, la junta general no es exactamente una junta espontánea; suele venir precedida, más bien, de una convocatoria informal que permite eludir los trámites de una convocatoria regular, que dilatan la intención de reunirse en junta habiendo necesidad de hacerlo por el bien de la sociedad. Por ello, se prescinde de la formalidad de la convocatoria, pero a condición de que asistan a sesión todos los accionistas, que todos estén de acuerdo en los temas a tratar en la sesión, y que todos suscriban el acta, pudiendo prescindirse de este requisito si es que todos los accionistas han firmado la lista de asistencia que se inserta al acta. La junta universal no es pues una junta general de accionistas que cuente con la presencia de la totalidad de accionistas, la diferencia está en que en la primera no se requiere la convocatoria, mientras que en la segunda es requisito de validez de los acuerdos de la junta la convocatoria con la formalidad establecida en la ley. Además, resulta importante resaltar que en las juntas generales realizadas con convocatoria, es suficiente que el acta la firme y la apruebe válidamente el presidente de la junta, el secretario y uno o dos accionistas, según lo decida la junta en el momento de la redacción del acta. En cambio, en el acta de la junta universal no existe esta delegación de facultades para suscribir el acta y aprobarla válidamente.

\section{La constitución de la junta, la asistencia y la representación del socio}

Para que se constituya la junta debe contarse con un número mínimo de titulares de acciones con derecho a voto. Cumplido el requisito de esta asistencia, se declara constituida la junta por contarse con el quórum necesario; de no ser así, habrá que esperar a lo que resulte de la segunda convocatoria. Si en la segunda convocatoria se cuenta con el número suficiente de titulares de acciones, entonces la junta podrá llevarse a cabo. Si en la segunda oportunidad no se puede cumplir con el número mínimo establecido por la ley, entonces habrá que volver a convocar por primera vez con las formalidades y requisitos mínimos establecidos por la ley.

Como nos dice el profesor Uría (1999, p. 310), en la legislación española se ha superado la interpretación que requería siempre la presencia de más de un accionista para formar junta, habida cuenta que por definición la junta era la reunión de accionistas, es decir, de varios y no de uno solo. En efecto, esta interpretación ha sido superada en la aplicación de la norma española, y en lo que se refiere a nuestra realidad, el artículo 125, último párrafo, señala: “En todo caso podrá llevarse a cabo la 
Junta, aun cuando las acciones representadas en ella pertenezcan a un solo titular". Ello, en realidad, en razón de que la reunión en junta general congrega a los titulares de acciones y el quórum y voto se fijan en función de cada acción, y como nos refería Joaquín Garrigues (1987) en su obra de derecho mercantil, debemos imaginar que cada acción es una persona, pues los votos son emitidos por acción.

La ley ha establecido el requisito del quórum en función de la relevancia de los asuntos a tratar en la junta. Así, habrá asuntos a tratar que no son trascendentales para los intereses de la sociedad, y en tal caso la presencia de accionistas es más flexible. Por eso, la ley señala que cuando se tratan temas que no son calificados como trascendentales, el quórum o presencia de los accionistas en primera convocatoria debe contar con la presencia de por lo menos el $50 \%$ del total de las acciones suscritas con derecho a voto; en segunda convocatoria, basta que se presente cualquier número de accionistas para que se pueda constituir el quórum. Los acuerdos se adoptan válidamente con el voto mayoritario del total de los accionistas presentes en la junta.

Los casos clasificados como quórums especiales son los supuestos referidos en el artículo 126 de la LGS, que dispone que: para que la junta general adopte válidamente acuerdos relacionados con los asuntos mencionados en los incisos 2, 3, 4, 5 y 7 del artículo 115, es necesaria, en primera convocatoria, cuando menos, la concurrencia de dos tercios de las acciones suscritas con derecho a voto. Estos temas están referidos a asuntos relacionados con la modificación del estatuto, aumento o reducción del capital, emisión de obligaciones, disposición de activos fijos por encima del $50 \%$ de su valor contable, fusiones o escisiones de sociedades, transformaciones, disolución y liquidación de la sociedad. En estos casos, en primera convocatoria es necesario, cuando menos, la concurrencia de dos tercios de las acciones suscritas con derecho a voto. En segunda convocatoria basta la concurrencia de al menos tres quintas partes de las acciones suscritas con derecho a voto.

Para la adopción del acuerdo válidamente, es con un número de votos por acción que represente, cuando menos, la mayoría absoluta de las acciones suscritas con derecho a voto. Es decir, se trata de fijar una referencia al total de las acciones suscritas con derechos y no tan solo a la mayoría de las acciones que se encuentran en la sesión. La ley permite que el estatuto pueda establecer quórum y mayorías superiores a los señalados. 


\section{El quórum y la adopción de acuerdos en las sociedades anónimas abiertas}

El criterio que subyace en las sociedades anónimas abiertas, es proteger el interés del inversionista, quien muchas veces no ha llegado a establecer lazos de relación personal con los demás socios. Subsiste un interés económico, por encima de una relación intuito personae para la formación de la sociedad. Lo que interesa a los socios es que el vehículo de la inversión llamada sociedad anónima prospere, defendiéndose los intereses sociales antes que los intereses individuales, como debe ser; por tanto, cualquier traba para la adopción de decisiones mayoritarias en el seno de la junta general de accionistas debe desaparecer. No es posible trabar la constitución de una junta general de accionistas por el hecho de que un grupo significativo de accionistas no concurra para dar quórum para la constitución de la sociedad. Ese escollo lo supera la sociedad anónima abierta, bajo el marco filosófico según el cual primero se debe proteger a la sociedad, porque ello trae el beneficio económico de la sociedad y a la larga el de los socios. Es así como en la sociedad anónima abierta no existen asuntos clasificados para los cuales se requiera en junta la concurrencia de un número mínimo de titulares de acciones para formar el quórum, ni para la decisión de acuerdos válidos; tampoco se hace referencia a una mayoría calificada, como en el caso de las sociedades anónimas ordinarias, o en la sociedad anónima cerrada.

La junta general de accionistas de una sociedad anónima abierta se constituye, en primera convocatoria, con la presencia de accionistas que representen el $50 \%$ del total de las acciones suscritas con derecho a voto; en segunda convocatoria, es suficiente la presencia de titulares de acciones que representen el $25 \%$ del total de los accionistas suscritos con derecho a voto; y en la tercera convocatoria, la junta se puede constituir con cualquiera que sea el número de accionistas titulares de acciones con derecho a voto concurrentes a la sesión.

Para efecto de los acuerdos, estos se consideran válidos si se adoptan con la mayoría absoluta del total de las acciones con derecho a voto, concurrentes a la junta.

\section{La asistencia a la junta general}

La asistencia a la junta está reservada para los socios, en ella se tratan asuntos que son de interés del socio. Sin embargo, la ley (artículo 121) 
permite que otras personas asistan a la junta general, como los directores y el gerente general, que no siendo accionistas pueden asistir a la junta general con voz pero sin voto. Además, se puede disponer la asistencia, con voz pero sin voto, de funcionarios, profesionales y técnicos al servicio de la sociedad, o de otras personas que tengan interés en la buena marcha de los asuntos sociales; para este caso, ello debe estar autorizado por el estatuto, por la misma junta general, o por el directorio. En este caso habrá que advertir que la presencia en junta es solo de los accionistas, debiendo entenderse que nada impide que concurra por derecho propio el titular de acción sin derecho a voto, pues la ley solo le ha suprimido su derecho a votar, pero no a deliberar. En cuanto a los funcionarios o profesionales que gozan de esta prerrogativa, ello es posible en la medida en que exista la autorización del órgano societario; sin embargo, llama la atención que siendo una facultad de la junta y propiamente una sesión de la junta, la ley permita que por acuerdo de directorio concurra una persona a la junta no obstante no ser accionista, ello en tanto se trate de una persona que tenga interés en la buena marcha de la sociedad y no en el interés individual de un socio; y en segundo lugar, por cuanto los profesionales de la sociedad suelen explicar los temas propios manejados administrativamente por el directorio, supuesto en el cual es pertinente la asistencia de un gerente de línea para que explique aquellos detalles que un gerente general no puede explicar con la claridad que el caso merezca. Es, en este caso, de interés del directorio que asista la persona idónea para dar las explicaciones pertinentes.

La ley considera que tienen derecho a asistir a la junta general de accionistas los titulares de acciones con derecho a voto que figuren inscritos a su nombre en la matrícula de acciones, con una anticipación no menor de dos días al de la celebración de la junta general. Cabe señalar que en el caso de las sociedades anónimas abiertas, esta anticipación es de diez días.

Por otro lado, el artículo 122 de la LGS señala que el accionista con derecho a participar en las juntas generales puede hacerse representar por otra persona. Con lo cual se nos advierte que pudiera ser que existieran accionistas que no pueden participar en junta y por tanto tampoco pueden estar representados. Al respecto, la limitación se aplica para aquellos casos en que, si bien el titular de la acción aparece inscrito como tal en el registro de matrícula de acciones, su registro ha sido tardío y por ello no tiene derecho a concurrir a la junta, a pesar 
de que al momento de la sesión aparezca o demuestre ser titular de acciones con derecho a voto. En similar situación puede estar un accionista que se encuentra en situación morosa, por lo que, aplicando el artículo $79^{13}$ de la LGS, sus acciones no dan quórum ni otorgan voto. Si no pueden asistir estos directamente, menos lo pueden hacer a través de sus representantes.

Por otra parte, el artículo 121 dispone que el estatuto puede limitar la facultad de representación, reservándola a favor de otro accionista, o de un director o gerente, ello con el propósito de que se mantengan bajo reserva, entre los mismos socios y órganos administrativos de la sociedad, los temas materia de la sesión; es una forma de administrar la reserva societaria. En el caso de las sociedades anónimas ordinarias, esta reserva de facultad representativa del accionista debe constar en el estatuto, y para la sociedad anónima cerrada, la norma limitativa de concurrencia nace de la ley, pues el artículo $243^{14}$ restringe la representación, pudiendo otorgarse a otro accionista, su cónyuge o ascendiente o descendiente en primer grado. No obstante esta limitación, a la inversa de lo que ocurre con el artículo 121, el estatuto puede extender la representación a otras personas, con lo cual se abre la posibilidad de representación del titular de las acciones con derecho a voto.

La LGS trae una limitación cuando se trata de la representación de las acciones en junta, y al respecto el artículo 90 exige, salvo que el estatuto disponga lo contrario, que todas las acciones pertenecientes a un accionista deben ser representadas por una sola persona, salvo disposición distinta del estatuto o cuando se trata de acciones que pertenecen individualmente a diversas personas pero aparecen registradas en la sociedad a nombre de un custodio o depositario.

13 Artículo 79 LGS: El accionista moroso no puede ejercer el derecho de voto respecto de las acciones cuyo dividendo pasivo no haya cancelado en la forma y plazo a que se refiere el artículo anterior.

Dichas acciones no son computables para formar el quórum de la junta general ni para establecer la mayoría en las votaciones. Tampoco tendrá derecho, respecto de dichas acciones, a ejercer el derecho de suscripción preferente de nuevas acciones ni de adquirir obligaciones convertibles en acciones.

14 Artículo 243: El accionista sólo podrá hacerse representar en las reuniones de junta general por medio de otro accionista, su cónyuge o ascendiente o descendiente en primer grado. El estatuto puede extender la representación a otras personas. 
Cuando las acciones pertenecientes a un mismo accionista son representadas por más de una persona porque así lo permite el estatuto, los derechos de impugnación de acuerdos y de separación de la sociedad solo se pueden ejercer cuando todos los representantes del accionista manifiesten su voluntad de impugnar el acuerdo o de separarse de la sociedad. Se defiende en este caso la unicidad del voto de todas las acciones, para poder ejercer los derechos especiales de minoría que la ley otorga al accionista disidente.

Para el supuesto de las sociedades anónimas abiertas, se sigue aplicando el artículo 121, con lo cual la limitación de representación del accionista es facultativa. En cuanto a la formalidad de la representación, esta debe constar por escrito y con carácter especial para cada junta general. Cuando se trate de poder especial puede constar en documento simple o en escritura pública, y será válido para la sesión de junta indicada ${ }^{15}$; y de presentarse el titular de la acción, se presume la revocatoria del poder; en cambio, si el poder es por escritura pública y otorgado en forma general, ante la presencia del accionista, este poder queda en suspenso para ser ejercido en otras sesiones. Basta que el poder sea otorgado por carta simple, siempre que se use en la sesión de junta general indicada en el documento.

El régimen de revocatoria de poderes antes indicado no opera cuando los poderes se han otorgado en forma irrevocable, en cuyo caso depende del plazo o del objeto a cumplir con el poder; o cuando se trata de pactos de sindicación de voto de acciones, en donde los accionistas han cedido sus derechos para el ejercicio de sus derechos en junta. Los poderes deben ser registrados ante la sociedad con una anticipación no menor de veinticuatro horas a la hora fijada para la celebración de la junta general.

La asistencia a la junta general se registra en forma antelada a la sesión, siendo esta una forma clara y precisa de confirmar que el quórum se fija al inicio de la sesión de junta general, de forma tal que una vez obtenido el número mínimo de asistentes que permita sesionar, la

15 Artículo 122: [...] La representación ante la junta general es revocable. La asistencia personal del representado a la junta general producirá la revocación del poder conferido tratándose del poder especial y dejará en suspenso, para esa ocasión, el otorgado por escritura pública. Lo dispuesto en este párrafo no será de aplicación en los casos de poderes irrevocables, pactos expresos u otros casos permitidos por la ley. 
junta se puede instalar; no afecta al quórum el retiro del accionista durante la sesión. Para facilitar la aplicación de este criterio, la LGS, en el artículo 123, señala: "Antes de la instalación de la junta general, se formula la lista de asistentes expresando el carácter o representación de cada uno y el número de acciones propias o ajenas con que concurre, agrupándolas por clases si las hubiere".

Un tema superado respecto a la asistencia y al quórum necesario para sesionar, es el relativo al interés de la asistencia del accionista, en los casos de las sociedades ordinarias y las sociedades anónimas cerradas, cuando se requiera concurrencia distinta para la formación del quórum. Así, por ejemplo, en el caso de la modificación de estatuto, se requiere contar en primera convocatoria con dos tercios de las acciones suscritas con derecho a voto, en tanto que en segunda convocatoria, con las tres quintas partes, y a su vez la convocatoria también se hace para que en la misma sesión se elija al directorio, supuesto en el cual el quórum necesario sería solo $50 \%$ del total de las acciones suscritas en primera convocatoria. En tal supuesto, la ley permite que un accionista así lo señale expresamente y deje constancia al momento de formularse la lista de asistentes; sus acciones no serán computadas para establecer el quórum requerido para tratar alguno o algunos de los asuntos de quórum calificado, con lo cual su presencia solo se computará para los otros temas.

Se protege de esta forma el interés del accionista respecto a otorgar presencia o no para la formación del quórum a los asuntos que son de su interés, y en resguardo de sus intereses puede negar con su ausencia el quórum necesario para los temas que requieren quórum calificado.

La lista de accionistas debe garantizar en forma clara esta diferenciación o la facilidad para el ejercicio de este derecho de asistencia. Los accionistas que ingresen luego de iniciada la sesión y formado el quórum, pueden participar con sus intervenciones y votar. Es importante tomar nota de la presencia de estos accionistas tardíos, por cuanto deben aparecen siempre anotados en el acta, dado que al establecer la mayoría de los acuerdos se les debe computar dentro de los votos emitidos en la sesión.

\section{Constancia de los acuerdos}

Para los acuerdos adoptados en una sesión, deben constar el lugar, la fecha y hora en que se realizó, y la indicación de si se celebra en pri- 
mera, segunda o tercera convocatoria; en este último caso, cuando se trata de actas de juntas generales de las sociedades anónimas abiertas. También debe indicarse el nombre de los accionistas presentes o de quienes los representen; el número y clase de acciones de las que son titulares; los nombres de quienes actuaron como presidente y secretario; la indicación de las fechas y los periódicos en que se publicaron los avisos de la convocatoria; la forma y resultado de las votaciones y los acuerdos adoptados.

El acta debe ser aprobada, y para ello es importante relevar la presencia del presidente de la junta y del secretario, pues como señala el artículo 129, la junta general es presidida por el presidente del directorio. El gerente general de la sociedad actúa como secretario, y en ausencia o impedimento de estos, desempeñan tales funciones aquellos concurrentes que la propia junta designe. Al respecto, se permite que el estatuto señale quién es la persona que preside la junta general de accionistas.

El gerente general, o quien actúe como secretario, tiene como encargo redactar el acta dentro de los cinco días siguientes a la celebración de la junta general. Corresponde al presidente, al secretario y a un accionista designado por los miembros de la junta, la aprobación del acta en la misma junta; ella debe contener constancia de dicha aprobación y ser firmada por estas personas; en cambio, cuando el acta no se aprueba en la misma junta, se designará a no menos de dos accionistas para que, conjuntamente con el presidente y el secretario, la revisen y aprueben. El acta debe quedar aprobada y firmada dentro de los diez días siguientes a la celebración de la junta, y será puesta a disposición de los accionistas concurrentes o de sus representantes, quienes podrán dejar constancia de sus observaciones o desacuerdos mediante carta notarial. La ley da validez legal al acta a partir de la aprobación. Enrique Elías nos refiere (2000, p. 364) que debe distinguirse entre los requisitos de convocatoria, quórum y votaciones, cuya inobservancia determina la nulidad de los acuerdos, de aquellos establecidos por los requisitos para el contenido del acta, a que se refiere el artículo 135 de la LGS, para que el acta cumpla la función de ser un medio fehaciente de prueba.

Nada impide que cualquier accionista concurrente a la junta pueda firmar el acta, y se le acoge el derecho de obtener copia certificada del acta, aunque no hubiese asistido a la junta general. Este derecho alcanza incluso a los accionistas sin derecho a voto. 


\section{Corolario}

La formación de la voluntad de la sociedad se da, pues, a través de los acuerdos mayoritarios formados en junta general de accionistas, y para ello la ley exige una serie de formalidades, que, como se ha indicado, son indispensables para que los acuerdos sean válidos, desde la convocatoria, asistencia y acuerdos adoptados; todo ello refleja el sentir de las decisiones de la voluntad societaria.

\section{Referencias}

Beaumont Callirgos, R. (2000). Comentarios a la Ley General de Sociedades. Lima: Gaceta Jurídica.

Elías, E. (2000). Derecho societario peruano (tomo I). Lima: Normas Legales. Garrigues, J. (1987). Curso de Derecho Mercantil. Bogotá: Temis.

Hundskopf Exebio, O. (2009). Manual de derecho societario. Lima: Grijley. Ley General de Sociedades.

Uría, R. (1999). Derecho mercantil (26a ed.). Madrid: Marcial Pons. 